\title{
Old-field Succession Sequence in Loess Area in Northern Shaanxi of China
}

\author{
Yaojun $\mathrm{Bo}^{\mathrm{a}, \mathrm{b}}$, Qingke Zhu ${ }^{\mathrm{b} *}$ and Weijun Zhao ${ }^{\mathrm{c}}$ \\ ${ }^{a}$ College of Life Sciences, Yulin University, Yulin, Shaanxi, 719000, China \\ ${ }^{b}$ College of Water and Soil Conservation, Beijing Forestry University, Beijing 100083, China
}

${ }^{c}$ Key Laboratory of Tourism and Resources Environment in Colleges and Universities of Shandong Province, Taishan University, Taian, Shandong 271021, China

\begin{abstract}
Hierarchical clustering method was applied for division of stages of old-field succession of loess area of Northern Shaanxi, and the similarity among different communities in abandoned field of different abandoned year and site condition can be learnt quantitatively, and stages or sequence of old-filed succession can be determined. The result revealed that the stages of old-field succession are: polydominant association of annual weed artemisia scoparia and other perennial herbage $\rightarrow$ Lespedeza davurica and perennial herbage association $\rightarrow$ artemisia vestita and perennial herbage association $\rightarrow$ tuft grass bothriochloa ischaemum and perennial herbage association $\rightarrow$ undershrub Buddleja alternifolia association. Among them, the appearance of shrub association (undershrub Buddleja alternifolia) contrasts results in former studies that it was impossible to form shrub association in loess area of Northern Shaanxi. Thus, this study is not only a complement of former studies, but also a new discovery and innovation.
\end{abstract}

Keywords: Community, Ecological restoration, Euclidean distance, Hierarchical clustering, Importance values of species, Succession sequence.

\section{INTRODUCTION}

Succession is one of the theoretical foundations of properly managing and using natural resources [1]. Old-field succession is an important type of secondary succession of vegetation [2]. Odum deemed that elements of ecological succession are closely associated with the relationship between human and nature, and are the foundation of resolving the contemporary environmental crisis [3]. At present, there are many reports about studies on old-field succession in Loess Plateau and loess area of Northern Shaanxi, for instance, the vegetation succession sequence in old-field succession [4-6], community composition and structure [7], composition of vegetation species [6], alteration of diversity of species [8, 9], features of primary productivity [10], functions of soil and water conservation [11], relationship between characteristics of vegetation and the environment and evolution of physical and chemical properties of soil $[12,13]$, etc.

The ecological environment of loess area of Northern Shaanxi is rather vulnerable with severe disruption and water and soil loss, which seriously restrains the sustainable development of regional socio-economy. Thus, the study on rules of old-field succession in this area will be of great significance in ecological restoration, development and utilization of natural resources, control of water and soil loss,

*Address correspondence to this author at the College of Water and Soil Conservation, Beijing Forestry University, Beijing 100083, China;

Tel: +86-10-6233-6083; Fax: +86-10-6233-6083;

E-mail: zhuqingke2013@126.com improvement of the environment, promotion of regional sustainable development, construction of ecological civilization.

\section{MATERIALS AND METHODS}

\subsection{Overview of the Study Area}

The study area Wuqi County is situated in the northwest of Yan'an City, (N36 $33^{\prime} 33^{\prime \prime}-37^{\circ} 24^{\prime} 27^{\prime \prime}$,E107 $38^{\prime} 57^{\prime \prime}-$ $\left.108^{\circ} 32^{\prime} 49^{\prime \prime}\right)$ with an altitude of 1233 to $1890 \mathrm{~m}$. Its landform belongs to typical hilly-gully region of Loess Plateau. Its climate model is semi-arid temperate continental monsoon climate, with an annual average temperature of $7.8^{\circ} \mathrm{C}$ and with an accumulated temperature of $\geq 10^{\circ} \mathrm{C}$ reaching $2817.8^{\circ} \mathrm{C}$. Its average annual sunlight hour is $2400 \mathrm{~h}$. Its frostfree period is $96-146 \mathrm{~d}$. Its annual average rainfall is $478.3 \mathrm{~mm}$, and the average amount of land evaporation of many years is $400-450 \mathrm{~mm}$ [14]. Its rainy season is from July to September, during which the precipitation account for $50 \%-80 \%$ of that of the whole year. The precipitation in other times are mainly invalid precipitation, and natural disasters like drought, hail, rainstorm, blustery and frost injury happen frequently. The soil in this area is mainly loessal soil.

Since 1998, Wuqi County closed hillsides to facilitate afforestation, and grazing has been banned in the whole basin, and applied artificial cultivation for vegetation restoration. At present, the vegetation in the basin is mainly herbosa. Among them, the main species include artemisia scoparia, artemisia vestita, artemisia giraldii pamp, stipa bungeana trin, lespedeza davurica, potentilla chinensi, 
bothriochloa ischaemum and buddleja alternifolia. In dissected valleys there are distributions of shrubs, and in lowland of river valley there are fragmentary distributions of arbors and shrubs.

\subsection{Layout of the Sampling Plot and Investigation Method}

In July of 2012, by replacing time sequence with spatial sequence, different plant communities naturally reserved in different abandoned year were chosen as object of investigation and study. In total, 29 sample fields were investigated. Typical sampling was applied in setting sample fields with shrub quadrat of $5 \mathrm{~m} \times 5 \mathrm{~m}$ and herb quadrat of $1 \mathrm{~m} \times 1 \mathrm{~m}$. And 10 quadrats were measured in each herbal sampling field. In each shrub quadrat, 1 shrub quadrat and 10 herbal quadrats were set. The record mainly includes: abandoned year, gradient, exposure, slope position, microtopography of a certain quadrat, community type, soil type, quantity, cover degree, above-ground biomass, height, frequency, abundance, altitude and number of plant (or number of clusters) etc.(Table 1).

Table 1. General status of sampling plot.

\begin{tabular}{|c|c|c|c|}
\hline Sample Number & Year of Returning & Exposure & Community Type \\
\hline 1 & 2 & Sunny slope & Salsola collina + Sonchus oleraceus \\
\hline 2 & 3 & Sunny slope & Artemisia scoparia \\
\hline 3 & 3 & semi-shady slope & Artemisia scoparia \\
\hline 4 & 3 & Semi-sunny slope & Artemisia scoparia \\
\hline 5 & 4 & Shady slope & Artemisia scoparia \\
\hline 6 & 4 & Semi-shady slope & Artemisia scoparia + Setaria viridis \\
\hline 7 & 5 & Shady slope & Artemisia scoparia + Heteropappus altaicus \\
\hline 8 & 5 & Shady slope & Artemisia scoparia+lespedeza davurica \\
\hline 9 & 6 & Shady slope & Lespedeza davurica + Heteropappus altaicus \\
\hline 10 & 6 & Semi-shady slope & Lespedeza davurica + Potentilla chinensis \\
\hline 11 & 7 & Semi-shady slope & Lespedeza davurica + Potentilla chinensis \\
\hline 12 & 7 & Semi-shady slope & Lespedeza davurica + Potentilla chinensis \\
\hline 13 & 8 & Semi-shady slope & Lespedeza davurica+Artemisia vestita \\
\hline 14 & 8 & Semi-sunny slope & Lespedeza davurica + Artemisia vestita \\
\hline 15 & 10 & Sunny slope & Artemisia vestita + Leymus secalinus \\
\hline 16 & 11 & Semi-sunny slope & Artemisia vestita + Artemisia giraldii Pamp \\
\hline 17 & 11 & Semi-shady slope & Artemisia vestita + Artemisia giraldii Pamp \\
\hline 18 & 12 & Shady slope & Artemisia vestita + Artemisia giraldii Pamp \\
\hline 19 & 12 & Shady slope & Artemisia vestita + Artemisia giraldii Pamp \\
\hline 20 & 13 & Semi-shady slope & Artemisia vestita + Artemisia giraldii Pamp \\
\hline 21 & 13 & Semi-shady slope & Artemisia vestita + Artemisia giraldii Pamp \\
\hline 22 & 14 & Semi-sunny slope & Artemisia vestita + Artemisia giraldii Pamp \\
\hline 23 & 14 & Semi-sunny slope & Artemisia vestita + Stipa bungeana \\
\hline 24 & 17 & Shady slope & Artemisia vestita + Stipa bungeana \\
\hline 25 & 19 & Semi-shady slope & Bothriochlia ischaemum+Artemisia vestita \\
\hline 26 & 22 & Shady slope & Bothriochlia ischaemum + Artemisia vestita \\
\hline 27 & 29 & Semi-shady slope & Bothriochlia ischaemum + Poa sphondylodes \\
\hline 28 & 40 & Semi-shady slope & Buddleja alternifolia \\
\hline 29 & 43 & Semi-sunny slope & Buddleja alternifolia \\
\hline
\end{tabular}




\subsection{Calculation of Importance Values of Species}

The important value is a comprehensive quantitative indicator that fully reflects the position and function of a certain plant in a community [15]. The variation tendency of heterogeneity in each stage of the succession of plant community reflects the evolutionary tend of the interaction between the community and the environment, and the characteristics of the community in each stage are presented by the variation of the important values. Thus, in this paper, important value is an important criterion. Its computational formula is:

$$
I=\frac{\text { Relative abundance }+ \text { Relative height }+ \text { Relative coverage }}{3}
$$

\subsection{Division of Each Succession Stage}

In July Population size of the community is indicated by the importance value of species. For division of community, association type and succession stage, hierarchical cluster analysis is applied in classification of sampling plots of different abandoned year. Hierarchical cluster analysis was conducted with the relative importance values of each species. The relative importance values were calculated by combining 10 quadrats in a sampling plot. First, coefficients of Euclidean distance between each two sampling plots were calculated. Then, hierarchical clustering was conducted by UPGMA [16]. Selection of cut-out values in hierarchical clustering method is based on the principle of being divided into the same association.

Coefficient of Euclidean distance $\left(\Delta_{j k}\right)$ :

$\Delta_{j k}=\sqrt{\sum_{i=1}^{n}\left(x_{i j}^{2}-x_{i k}^{2}\right)}$

\section{RESULTS AND DISCUSSIONS}

\subsection{Changes of Community in Different Abandoned Year}

According to the important value of each species in sampling plot, there are in total 14 community types in abandoned land (Table 1). Among these, dominant species are mainly annual weed salsola collina and artemisia scoparia, perennial herb lespedeza davurica and artemisia vestita, bothrioch loa ischaem um, shrub buddleja alternifolia. Fields abandoned in less than 5 years, including Sampling plot 2, 3, 4 and 5, are all artemisia scoparia monodominant community or polydominant community (sampling plot 1, 6, 7 and 8). For fields abandoned in 6 to 8 years, there are mainly 3 community types, namely polydominant community consisting of Heteropappus altaicus, Lespedeza davurica, potrntilla and artemisia vestita. For fields abandoned in 10 to 17 years, there are mainly 3 community types, namely polydominant community consisting of artemisia vestita, leymus, bungeana trin and Artemisia giraldii Pamp. For fields abandoned in 19 to 29 years, there are mainly 2 community types, namely polydominant community consisting of bothriochloa ischaemum, artemisia vestita and poa sphondylodes. For fields abandoned in 40 to 43 years, there are mainly 1 community types, namely the monodominant community consisting of the shrub buddleja alternifolia.

Regardless of site conditions like terrain factors, according to the abandoned year of each community type (Table 1), the general community succession tendency of loess area of Northern Shaanxi is: in preliminary stage of returning farmland to woodland, the main community is in general monodominant community of artemisia scoparia, or polydominant communityconsisting of salsola collina, artemisia scoparia, sonchus oleraceus, green bristlegrass, heteropappus altaicus, lespedeza davurica, etc. This stage lasts for 2 to 5 years. And other communities according to the abandoned year of the field are respectively: community of lespedeza davurica $\rightarrow$ community of artemisia vestita $\rightarrow$ community of bothriochloa ischaemum $\rightarrow$ community of buddleja alternifolia. In the field having returned the farmland for more than 6 years, lespedeza davurica begin to dominant and its community takes the place of the community of artemisia scoparia. After that, community with artemisia vestita and Bothriochloa ischaemum as dominant species comes into being. The seed of artemisia vestita is relatively big and the vitality of its seedling is very strong, while that of Bothriochloa ischaemum is small and although its diffusion distance is relatively farther, the vitality of its seedling is weak and its survival rate is low. Thus, the distribution range of artemisia vestita is wider (in 10 sampling plots), while that of bothriochloa ischaemum is smaller (in 3 sampling plots). Finally, there is community of buddleja alternifolia, which completes the succession process of the stage of old-field succession of shrub and herbaceous plant.

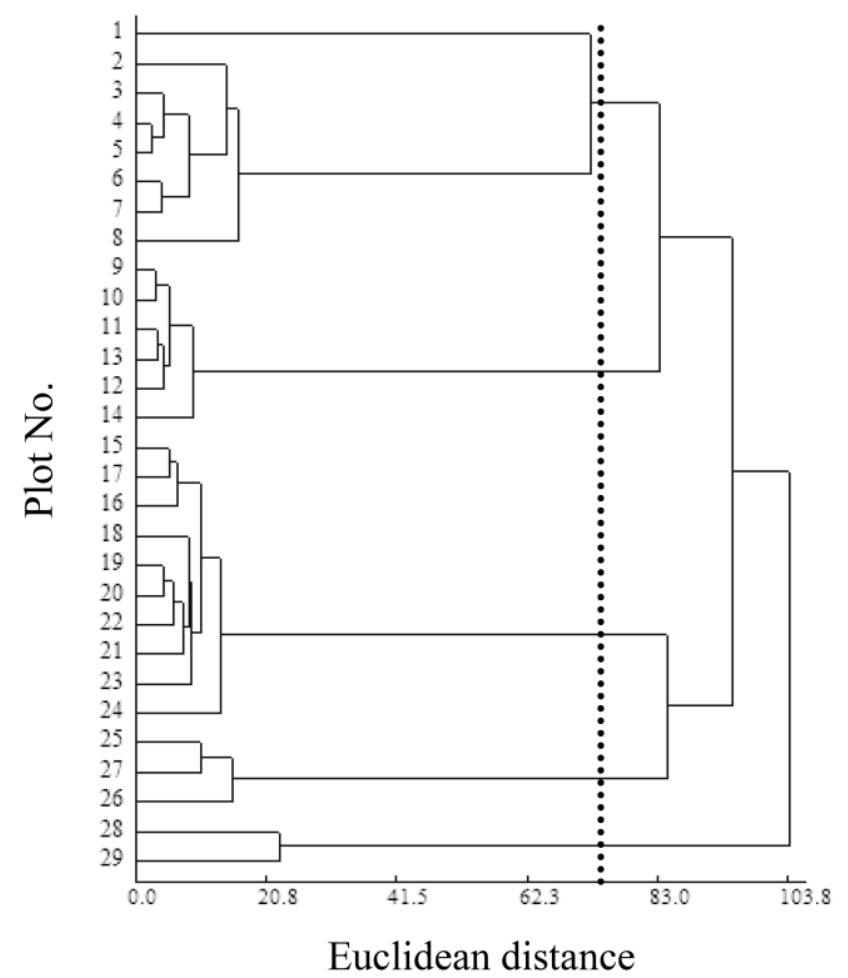

Fig. (1). Tree dendrogram of system clustering of communities in old-land. 


\subsection{Clustering Analysis of Communities of Different Abandoned Year}

The result of hierarchical clustering of serial community in old-field succession reveals that (Fig. (1)) when the cutout value is 73.0, all the community quadrats cluster into 5 categories: $I=\{1,2,3,4,5,6,7,8\}, I I=\{9,10,11,13,12$, $14\}, \mathrm{III}=\{15,17,16,18,19,20,22,21,23,24\}, \mathrm{IV}=\{25,27$, $26\}, V=\{28,29\}$.

The abandoned year of association of annual weed artemisia scoparia andpolydominant association I consisting of annual weed salsola collina, artemisia scoparia and other perennial grass is 2 to 5 years and 3. 6 years in average. The abandoned year of Association II consisting of perennial herb lespedeza davurica and the other perennial herbaceous is 6 to 8 and 7 years in average. The abandoned year of Association III consisting of perennial herb artemisia vestita and perennial herb is 10 to 17 years and 12.7 years in average. The Abandoned year of Association IV consisting of Bothrioch loa ischaem um and other perennial herbs is 19 to 29 year and 23.3 years in average. The abandoned year of association $\mathrm{V}$ consisting of buddleja alternifolia is 40 to 43 years and 41.5 years in average. From the perspective of association types and according to the abandoned year, the succession sequence of old-field succession of shrub and herbaceous plant in loess area of Northern Shaanxi is: the polydominant association of annual herb artemisia scoparia and other perennial grass $\rightarrow$ association of lespedeza davurica and perennial grass $\rightarrow$ association of artemisia vestita and perennial grass $\rightarrow$ association of bunch grass bothriochloa ischaemum and perennial grass $\rightarrow$ association of undershrub Buddleja alternifolia. This succession sequence is different from the former result of the study of vegetation succession sequence of loess area of Northern Shaanxi by Qin Wei, etc. [5]. According to their research, the climax community of vegetation sequence of loess area of Northern Shaanxi is the zonal perennial herbaceous community and shrub community cannot form. Thus, this study is a supplement for the former studies on old-field succession sequence in loess area of Northern Shaanxi. Meanwhile, trees were fund in dissected valley and the bottom of the valley of the study area. However, due to the hard terrain, further investigation was not made, so whether the vegetation of this area can recover to arbor community calls for further study.

In the process of hierarchical clustering, the classification results made by using the original value of importance values of communities of each sampling plot and by using Euclidean distance coefficient tend to be uniform, but the result of division of community type by means of Euclidean distance coefficient is easier for explaining the stages of succession. UPGMA can properly maintain the spatial attribute of quadrats, and different dissimilar coefficient can be chosen for distance between each two quadrats, and there won't be matrix reverse.

\subsection{Characteristics of Serial Community}

The first stage of succession is association group of annual herb. Its main vegetation includes mainly artemisia scoparia, salsola collina, sonchus oleraceus, green bristlegrass, heteropappus altaicus and lespedeza davurica. And its secondary vegetation includes corispermum hyssopifolium
L, cirsium setosum, gueldenstaedtia stenophylla bunge, potentilla chinensis, calystegia hederacea, euphorbia humifusa, Agriophyllum squarrosum, sonchus arvensis,etc.. Among them, Sonchus arvensis and sonchus oleraceus are weeds with relatively strong root tiller, thus, they have a wide distribution before returning the farmland to the wood and in some districts, they can form dominant species in the preliminary stage of succession. Agriophyllum squarrosum and salsola collina can form dominant community in district with frequent man-made disturbance, like in the field and the roadside. Due to influences of environmental factors like soil moisture and nutrient of the sampling plot, and propagule in nearby grassland and soil seed bank, community types and floristic composition are abundant. Later as old-field succession goes on and the soil environment factors changes, in the 6th year, annual herbs decreases gradually and their vitality decline. Perennial plants begin to take the advantage and community species, composition and biomass all increase. In this stage, the main vegetations include lespedeza davurica, heteropappus altaicus, potentilla chinensis and artemisia vestita. Secondary vegetations include artemisia scoparia, agropyron cristatum, artemisia giraldii pamp, stipa bungeana trin, leymus secalinus and cleistogenes chinensis. And in the 10th to the 43rd year, artemisia vestita and bothriochloa ischaemum of strong competitive and occupation capability and the droughtenduring undershrub buddleja alternifolia begin to take the advantage, and species unable to endure drought and with weaker competitive capacity exit the community, and vegetation species composition reduces. In this stage, secondary vegetations and common species that include potentilla chinensis, poa sphondylodes, lespedeza davurica, artemisia lavandulaefolia, artemisia giraldii pamp, thymus mongolicus, stipa bungeana trin and stipa grandis, etc.

Though old-filed succession begins in secondary bare areas in abandoned fields, the influence of origin vegetation cannot be excluded. The direction and rate of succession will change with discrepancy of site condition and the environment, for example, exposure, gradient, physical and chemical properties of soil, soil moisture, nutrient, etc. Thus, when the regional general climate background and regional species distribution are relatively fixed, the rules of community succession in one region are generally determined by the adaptive capacity fertility, spread capacity and relative competitive ability of species.

\section{CONCLUSION}

Hierarchical clustering method was applied in division of stages of old-field sere succession of shrub and herbaceous plant in loess area of Northern Shaanxi, and the result is quite satisfactory. It can analyze the similarity of communities of different site condition and abandoned year. According to the average abandoned year of each association, the sequence of old-field association of loess area of Northern Shaanxi can be approximately determined.

\section{ABBREVIATION}

UPGMA = Unweighted pair-group method with arithmetic means 


\section{CONFLICT OF INTEREST}

The authors confirm that this article content has no conflict of interest.

\section{ACKNOWLEDGEMENTS}

This research was supported by the Special Fund for Forestry Scientific Research in the Public Interest (201104002-2), Agricultural Attack Project in Shaanxi Province (2014K01-12-03).

\section{REFERENCES}

[1] Bazzaz FA. Plant species diversity in old-field successional ecosystems in southern Illinois. Ecology 1975; 56(2): 485-8.

[2] Egler FE. Vegetation science concepts I. Initial floristic composition, a factor in old-field vegetation development. Vegetatio 1954; 4(6): 412-7.

[3] Odum EP, Barrett GW. Fundamentals of ecology. Philadelphia: Saunders Co 1971.

[4] Du F, Shan L, Chen XY, et al. Studies on the vegetation succession of abandoned farmland in the Loess hilly region of northern Shaanxi-succession series after being abandoned. Acta Agrestia Sinica 2005; 13(4): 328-33.

[5] Qin W, Zhu QK, Liu ZQ, et al. Study on natural seres of vegetation and plant species diversity on returning land for farming to forests and grassplots in the hilly-gully regions of the Loess Plateau. Arid Zone Research 2008; 25(4): 507-13.

[6] Cheng, JM, Wan, HE, Hu, XM. Study of Vegetation Restoration and Rebuilding Pattern and the Process of Succession in the Loess Hilly Regions. Acta Agrestia Sinica 2005; 13(4): 324-333.
[7] Du F, Shan L, Liang ZS. Studies on vegetation succession of abandoned arable land in loess hilly regions of northern of Shaanxi Province-analyses of community composition and structure. Acta Agrestia Sinica 2005; 13(2):140-258.

[8] Bai WJ, Jiao JY, Ma XH, et al. Classification and ranking of the forae naturally recuperating on the farming-withdrawn land in the hilly and gully regions of the loess plateau. Acta Botanica BorealiOccidentalia Sinica 2005; 25(7): 1317-22.

[9] Li YY, Shao MA. The change of plant diversity during natural recovery process of vegetation in zi wu ling area. Acta Agrestia Sinica 2004; 24(2): 252-60.

[10] Ma YS, Li QY, Lang BN, et al. The improvement and utilization on secondary salinized abandoned land in chaidamu basin. Prata Cultural Science 1997; 14(3): 17-20.

[11] Wang BK, Tang KL. The aetivities of waste land reclamation and its effects upon the accelerated soil erosion. Bull Soil Water Conserv 1991; 11(5): 54-60.

[12] Wang GH. Plant traits and soil chemical variables during a secondary vegetation succession in abandoned fields on the Loess Plateau. Acta Botanica Sinica 2002; 44(8): 990-8.

[13] Tang L, Liang ZS, Du F, et al. Vegetation succession of arable old land after being abandoned in Loess Plateau hilly region \& ascertaining dominant native herbages in the process, analyzing their chemical nutrient composition. Acta Ecologica Sinica 2006; 26(4): 1165-75.

[14] Bo YJ, Zhu QK, Zhao WJ. Characteristics of soil moisture in relation to microtopography in the Loess region of Northern Shaanxi, China. J Environ Biol 2014; 35(4): 741-9.

[15] Tilman D. Community invasibility, recruitment limitation, and grassland biodiversity. Ecology 1997; 78(1): 81-92.

[16] Tang QY, Feng MG. DPS data processing system for practical statistics. Beijing, China: Science Press 2002; pp. 333-339.

(c) Bo et al.; Licensee Bentham Open.

This is an open access article licensed under the terms of the Creative Commons Attribution Non-Commercial License (http://creativecommons.org/licenses/ by-nc/3.0/) which permits unrestricted, non-commercial use, distribution and reproduction in any medium, provided the work is properly cited. 